\title{
Measurement of the radical scavenging activity of chicken jelly soup, a part of the medicated diet, 'Yakuzen', made from gelatin gel food 'Nikogori', using chemiluminescence and electron spin resonance methods
}

\author{
NORIE NAGATSUKA ${ }^{1}$, KAZUKI HARADA $^{2}$, MAMI ANDO $^{3}$ and KEIKO NAGAO ${ }^{1}$ \\ ${ }^{1}$ Department of Food and Nutrition, Faculty of Home Economics, Tokyo Kasei University, 1-18-1 Kaga, Itabashi-ku, \\ Tokyo 173-8602; ${ }^{2}$ Laboratory of Marine Resource Processing, Department of Food Science and Technology, \\ National Fisheries University, 2-7-1 Nagata-Honmachi, Shimonoseki-shi, Yamaguchi 759-6595; \\ ${ }^{3}$ Department of Human Nutrition, Faculty of Human Life Science, Yamaguchi Prefectural University, \\ 3-2-1 Sakurabatake, Yamaguchi-shi, Yamaguchi 753-8502, Japan
}

Received January 9, 2006; Accepted February 13, 2006

\begin{abstract}
We reported that gelatin gel 'Nikogori' soup made from the collagen in chicken wing meat, which is a part of the medicated diet 'Yakuzen', has high peroxyl and hydroxyl radical scavenging activities as the antioxidative capacity using chemiluminescence and electron spin resonance methods. The peroxyl radical scavenging activity of the soy sauce and chicken jelly 'Nikogori' soup sample was much higher than that of the chicken-only sample (control) at $100^{\circ} \mathrm{C}$ heating for $60 \mathrm{~min}$, although the addition of soy sauce only slightly enhanced the hydroxyl radical scavenging activity. Although the addition of garlic slightly enhanced the hydroxyl radical scavenging activity, it strongly inhibited the peroxyl radical scavenging activity. We found that chicken jelly 'Nikogori' soup only and soup with the addition of soy sauce had the highest antioxidative capacity as part of the medicated diet, 'Yakuzen'.
\end{abstract}

\section{Introduction}

'Nikogori' is a gelatin gel used in Japanese traditional food, which is made by heating extracts from animal collagen. Jelly 'Nikogori' soup extracted from the scleroproteins of animals is used as an effective dietary supplement for advanced age and dysphagia persons due to its high protein

Correspondence to: Dr Keiko Nagao, Department of Food and Nutrition, Faculty of Home Economics, Tokyo Kasei University, 1-18-1 Kaga, Itabashi-ku, Tokyo 173-8602, Japan

E-mail: nagao@tokyo-kasei.ac.jp

Key words: radical scavenging, chicken jelly soup, Nikogori, Yakuzen, hydroxyl radical, peroxyl radical, electron spin resonance, chemiluminescence content, ease of swallowing and good source of water supply. The soup extracted from chicken has traditionally been used in Asia as 'yaoshan', i.e. Chinese medicated diet 'Yakuzen', to improve the circulatory system. Minari et al reported the relationship between Chinese medicated diet 'Yakuzen' and Chinese medicine (1), and classified the ingredients of 'Yakuzen' (2). The bone of chicken has high amounts of collagen and 'Umami'. Consequently, it is often used in soups as a source of jelly in Chinese and French cuisines. In our previous report, the radical scavenging activity of the gelatin gel food, 'Nikogori', made from collagens of fish and chicken wings, was measured using chemiluminescence, and it was verified that all 'Nikogori' samples possessed high levels of peroxyl radical scavenging activity, i.e. antioxidative capacity (3). Further, it has been clarified that oral consumption of collagen reduces symptoms of joint pain in mice (4). In the present study, various samples of jelly 'Nikogori' soup made from chicken, which is widely used in various styles of cooking, were prepared using different heating times, temperatures, and addition of various seasonings or spices, and then were examined for peroxyl and hydroxyl radical scavenging activities. The scavenging activities of peroxyl and hydroxyl radicals, which are considered to cause especially severe damage in vivo among oxygen radicals, were measured using chemiluminescence and electron spin resonance (ESR). Several observations on radical scavenging activity are discussed in this report based on the preparation of 'Nikogori' samples using various heating times and temperatures.

\section{Materials and methods}

Samples of chicken jelly soup. We used the wing meat of chicken from Iwate Pref., Japan for the chicken jelly 'Nikogori' soup. As seasonings or spices, soy sauce (Kikkoman Co., Noda, Japan), rice vinegar (Mitsukan Co., Aichi, Japan), wine (Merusyan Co., Tokyo, Japan), ginger (Kumamoto Pref., Japan), garlic (Aomori Pref., Japan), parsley (Ibaragi Pref., 
Japan) and celery (Nagano Pref., Japan) were used in this experiment.

Preparation of chicken soup. Fifty grams of chicken wings were sectioned crosswise into $10-\mathrm{mm}$ pieces, placed in a 500-ml heat-resistant beaker with $30 \mathrm{~g}$ of distilled water and heated. When the water started to boil, the heating was continued at $100^{\circ} \mathrm{C}$ or $90^{\circ} \mathrm{C}$ for $10,20,30,60,90$ and $120 \mathrm{~min}$, supplementing the distilled water. After heating for the predetermined time, the samples were filtered through a filter paper typically used for cooking and the filtrates (about $25 \mathrm{~g}$ ) were made up with water to a final weight of $30 \mathrm{~g}$. These samples were used as control samples. At the same time, other samples were prepared by adding seasonings (soy sauce, rice vinegar or wine) or spices (ginger, garlic, parsley or celery) of a $10 \%$ final concentration to the control sample, and then heated at $100^{\circ} \mathrm{C}$ for $60 \mathrm{~min}$.

Preparation of chicken jelly 'Nikogori' soup. Chicken jelly 'Nikogori' soup was prepared using $10 \mathrm{~g}$ of each sample soup placed in a petri dish (inner diameter, $32 \mathrm{~mm}$; depth, $15 \mathrm{~mm}$ ) and refrigerated at $5^{\circ} \mathrm{C}$ for $24 \mathrm{~h}$.

Chemicals. 2,2'-Azobis (2-amidinopropane) dihydrochloride (AAPH) (5) and sodium tetraborate decahydrate (borax) were obtained from Wako Pure Chemical Industries, Ltd. (Osaka, Japan). Luminol and cytochrome $c$ from horse heart were obtained from Nacalai Tesque (Kyoto, Japan). Hydrogen peroxide $\left(\mathrm{H}_{2} \mathrm{O}_{2}\right)$ was obtained from Santoku Chemical Industries Co., Ltd. (Tokyo, Japan); iron (II) sulfate heptahydrate $\left(\mathrm{FeSO}_{4} \cdot 7 \mathrm{H}_{2} \mathrm{O}\right)$ was from Sigma-Aldrich Japan K.K. (Tokyo, Japan); and 5,5-dimethyl-1-pyrroline $N$-oxide (DMPO), as a spin trapping reagent, was from Tokyo Kasei Kogyo Co., Ltd. (Tokyo, Japan).

Preparation of radical scavenging activity experiment sample. The chicken jelly 'Nikogori' soup was heated to $37^{\circ} \mathrm{C}$ to form a chicken soup solution. For exposure to heating, a water bath (Digi Thermopet NTT-1200, Eyela, Tokyo Rikakikai Co., Ltd., Tokyo, Japan) was used. The temperature was maintained at $\pm 0.03^{\circ} \mathrm{C}$.

Chemiluminescence experiment procedure. The method has been described previously in detail (6-9). In brief, AAPH (40 $\mathrm{mM}$ ) reagent was dissolved in $100 \mathrm{mM}$ phosphate buffer ( $\mathrm{pH}$ 7.0). The chicken soup solutions were also diluted to the desired concentration using the same buffer. AAPH solution heated at $37^{\circ} \mathrm{C}$ for 2 min generates peroxyl radicals. Then, the AAPH solution $(0.2 \mathrm{ml})$ was mixed with $0.2 \mathrm{ml}$ phosphate buffer as the control or mixed with $0.2 \mathrm{ml}$ diluted chicken soup solution as the sample, and the solution mixture was heated at $37^{\circ} \mathrm{C}$ for $2 \mathrm{~min}$. Immediately after heating, $0.2 \mathrm{ml}$ of the luminol solution was added to the mixture for the chemiluminescence measurement. For the luminol solution, luminol $(0.113 \mathrm{mM})$ and cytochrome $c(0.004 \mathrm{mM})$ were dissolved in a mixture of $100 \mathrm{mM}$ sodium tetraborate buffer ( $\mathrm{pH}$ 9.28), water and methanol (volume ratio 9:1:30). The final concentrations of AAPH, luminol and cytochrome $c$ were $13.333 \mathrm{mM}, 0.038 \mathrm{mM}$ and $0.001 \mathrm{mM}$, respectively. Chemiluminescence intensity was measured using a photon counter Lumitester C-100 (Kikkoman Co., Tokyo, Japan). One RLU (relative light unit) represents 43.48 photons/sec.

Electron spin resonance (ESR) experiment procedure. The electron spin resonance (ESR) method has been described previously (10-12) and explained as follows. Hydroxyl radicals were generated by Fenton's reaction. First, $50 \mu 1$ of $8.8 \mathrm{mM}$ $\mathrm{H}_{2} \mathrm{O}_{2}$ solution was added to $20 \mu \mathrm{l}$ of $90 \mathrm{mM}$ 5,5-dimethyl-1pyrroline $N$-oxide (DMPO) solution as a spin trapping reagent, and this mixing solution was further added to $250 \mu$ l chicken jelly 'Nikogori' soup solution for the sample or ultra pure water for the control. The ultra pure water was made using the ultrapure water purification system (Milli-Q Jr., Nihon Millipore Kogyo K.K., Yonezawa, Japan). Next, sample or control solution was added to $50 \mu \mathrm{FeSO}_{4}$ solution to initiate Fenton's reaction, which occurs as in the following chemical equation: $\mathrm{Fe}^{2+}+\mathrm{H}_{2} \mathrm{O}_{2} \rightarrow \mathrm{Fe}^{3+}+\cdot \mathrm{OH}+\mathrm{OH}^{-}$.

After 1 min of Fenton's reaction, the hydroxyl radical generation, i.e. spin adduct DMPO-OH•, was measured using the ESR spectrometer (JES-FR30, JEOL Ltd., Tokyo, Japan). The ESR measurement conditions were as follows: output, 4 $\mathrm{mW}$ (9.4 GHz); magnetic field, 342.790 $\pm 5 \mathrm{mT}$; modulation amplitude, $0.079 \mathrm{mT}$; response time, $0.1 \mathrm{sec}$; sweeping time, $1 \mathrm{~min}$; and amplification ratio, 32-125.

Calculation of $I C_{50}$ value of peroxyl or hydroxyl radical scavenging. As an indicator of the antioxidative capacity, the inhibition of chemiluminescence intensity or hydroxyl radical peak of ESR pattern was measured by the change of the RLU (relative light unit) value or peak height of ESR, respectively. The lower the RLU value or the peak height, the more inhibition of chemiluminescence intensity (peroxyl radical generation) or hydroxyl radical generation occurred, respectively. The value of $\mathrm{IC}_{50}$ was defined as the concentration of chicken jelly 'Nikogori' soup solution reducing the RLU value of phosphate buffer (control) or the control peak height of ESR to half. First, the antioxidative value was calculated using the following formula: $(\log \mathrm{Io} / \mathrm{I}) \mathrm{x} 100$; Io = RLU value or peak height of the control, I = RLU value or peak height of each concentration of chicken jelly 'Nikogori' soup solution sample.

When the value of this formula indicates 30.103 , the I value corresponds to the half-inhibition. Next, from the figure of the relationship between the antioxidative value and the concentration of the chicken jelly 'Nikogori' soup solution, $\mathrm{IC}_{50}$ values were obtained (3).

\section{Results and discussion}

The $I C_{50}$ value of chicken jelly 'Nikogori' soup with garlic spice. As shown in Fig. 1, the antioxidative values for the peroxyl radical scavenging activity of the chicken jelly 'Nikogori' soup with garlic spice sample showed a good linearity with the concentration of the sample added. Thus, we can determine the $\mathrm{IC}_{50}$ value concentration of the chicken jelly 'Nikogori' soup with garlic spice sample by showing the half-inhibition of the control chemiluminescence. Since an antioxidative value of $30.103(\log 2 \times 100)$ corresponds to the half-inhibition, the $\mathrm{IC}_{50}$ of the chicken jelly 'Nikogori' 


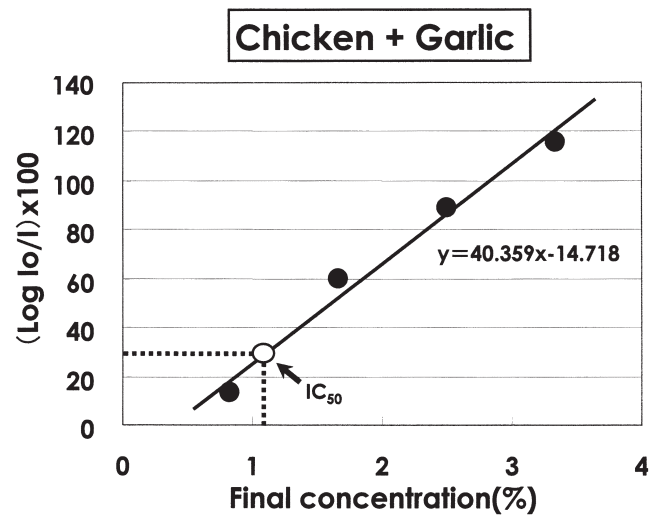

Figure 1. The relationship between the chemiluminescent yield and the final concentration of chicken jelly 'Nikogori' soup with garlic spice. The antioxidative value was calculated and plotted against the final concentration of the chicken jelly 'Nikogori' soup with garlic spice.

soup with garlic spice sample (chicken + garlic) was estimated to be $1.135 \%$ from the equation of the approximate linear relationship shown in the figure. By the same procedure, the $\mathrm{IC}_{50}$ values of the chicken jelly 'Nikogori' soup samples heated at $100^{\circ} \mathrm{C}$ and $90^{\circ} \mathrm{C}$ for $10-120$ min were obtained. Similarly, the $\mathrm{IC}_{50}$ values of the control sample with seasonings (soy sauce, rice vinegar, wine) or spices (ginger, parsley, celery) heated at $100^{\circ} \mathrm{C}$ for $60 \mathrm{~min}$ were obtained. From these data, the antioxidative capacity, i.e. the peroxyl radical scavenging activity, for each chicken jelly 'Nikogori' soup sample heated at $100^{\circ} \mathrm{C}$ and $90^{\circ} \mathrm{C}$ for various times and the soup samples with seasonings or spices was estimated. The antioxidative values of the hydroxyl radical scavenging activity were obtained using the same method as for the peroxyl radical scavenging activity.

The evaluation of antioxidative levels with various heating temperatures and times. Figs. 2 and 3 show the changes in peroxyl and hydroxyl radical scavenging activities of chicken jelly 'Nikogori' soup according to the differing cooking conditions. The data of $\mathrm{IC}_{50}$ values were compared among the various heating times and temperatures of chicken jelly 'Nikogori' soup. In typical cooking, heating at $100^{\circ} \mathrm{C}$ is used for a short time when boiling and seasoning food and approximately $90^{\circ} \mathrm{C}$ is used for a long time with soups. In this report, peroxyl and hydroxyl radical scavenging activities were defined as equal to the antioxidative capacity, the lower the height of the bars in the figure indicates a stronger antioxidant. As the heating time is extended and temperature elevated, the hydrolysis, autoxidation, and thermoxidation of lipids concomitantly increase (13). Thus, lipids which are released from the chicken wings into the soup and form layers or emulsions are assumed to be associated with lipid oxidation. In the 'Nikogori' samples in our research, this was also assumed. However, the 'Nikogori' samples are gelated by the collagen degradation products eluted into the soup and it has been reported that the collagen degradation products and collagen peptides possess antioxidative capacity (14). The relationship between peroxyl radical scavenging activity and heating temperature was investigated. The peroxyl radical scavenging activity of chicken jelly 'Nikogori' soups extracted

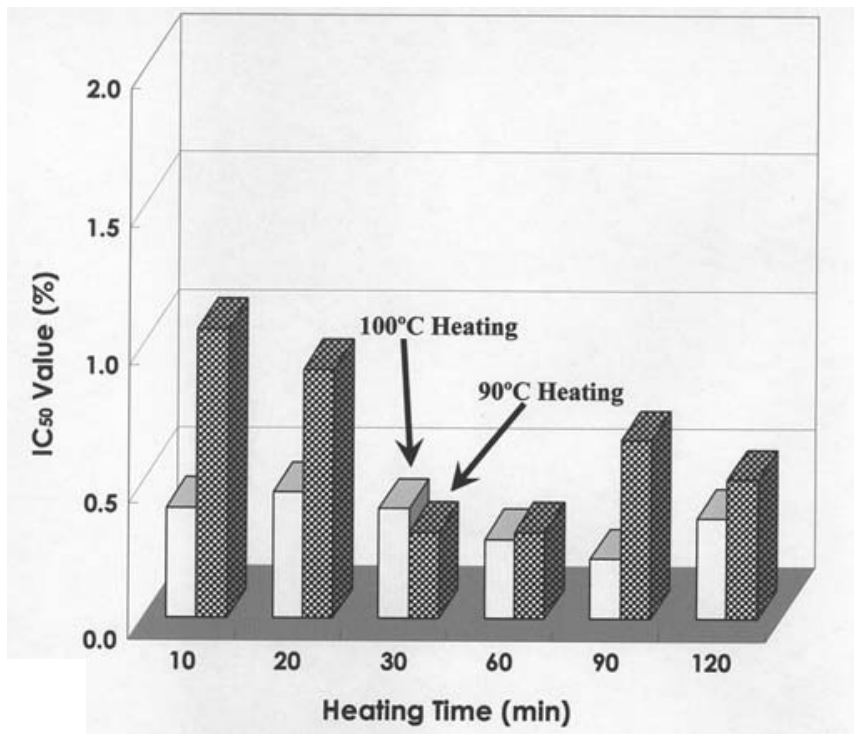

Figure 2. Effects of the heating temperature and time on the $\mathrm{IC}_{50}$ value (\%) of the peroxyl radical scavenging activity of the chicken jelly 'Nikogori' soup, measured using chemiluminescence. White bars indicate $100^{\circ} \mathrm{C}$ heating; and bars with squares, $90^{\circ} \mathrm{C}$ heating.

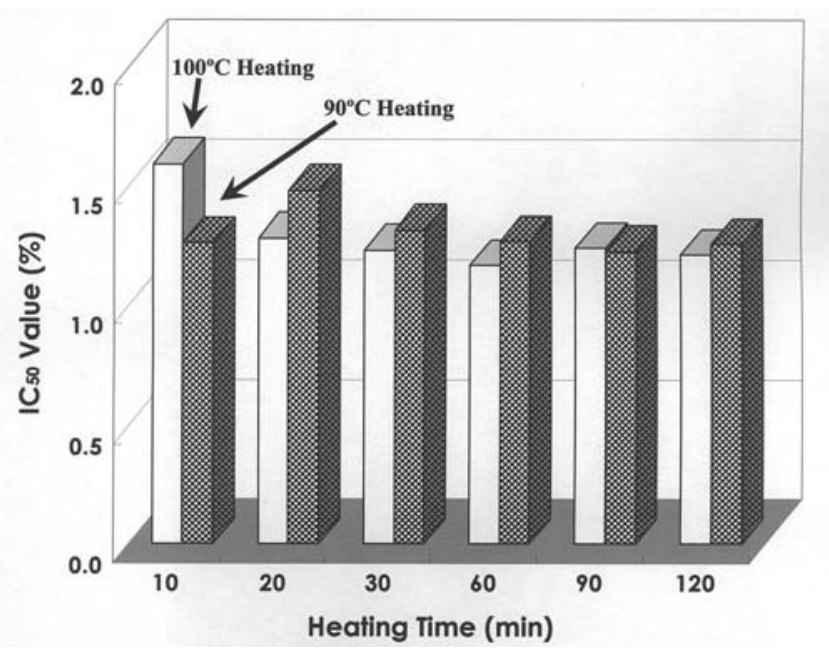

Figure 3. Effects of the heating temperature and time on the $\mathrm{IC}_{50}$ value (\%) of the hydroxyl radical scavenging activity of chicken jelly 'Nikogori' soup, measured using electron spin resonance (ESR). Details of the symbols of the bars are described in the legend of Fig. 2.

by heating at $100^{\circ} \mathrm{C}$ (average of $\mathrm{IC}_{50}$ value, $0.36 \%$ ) tended to be stronger than that of soups heated at $90^{\circ} \mathrm{C}$ for up to $120 \mathrm{~min}$ (average of $\mathrm{IC}_{50}$ value, $0.62 \%$ ) (Fig. 2). Further, the scavenging activity of peroxyl radical on samples cooked for up to $60 \mathrm{~min}$ at $90^{\circ} \mathrm{C}$ tended to be elevated. The $\mathrm{IC}_{50}$ values were $1.05,0.91$, 0.31 and $0.31 \%$ for $10,20,30$ and 60 min, respectively (Fig. 2). Therefore, it is assumed that the higher levels of peroxyl radical scavenging activity in chicken jelly 'Nikogori' soups extracted by high temperature at $100^{\circ} \mathrm{C}$, shown in Fig. 2, could inhibit lipid oxidation irrespective of the extracted heating time of the soup. On the other hand, the difference between hydroxyl radical scavenging activity at $90^{\circ} \mathrm{C}$ (average of $\mathrm{IC}_{50}$ value, $1.30 \%$ ) and $100^{\circ} \mathrm{C}$ (average of $\mathrm{IC}_{50}$ value, $1.28 \%$ ) for up to 120 min was minimal (Fig. 3); the activity at $100^{\circ} \mathrm{C}$ 


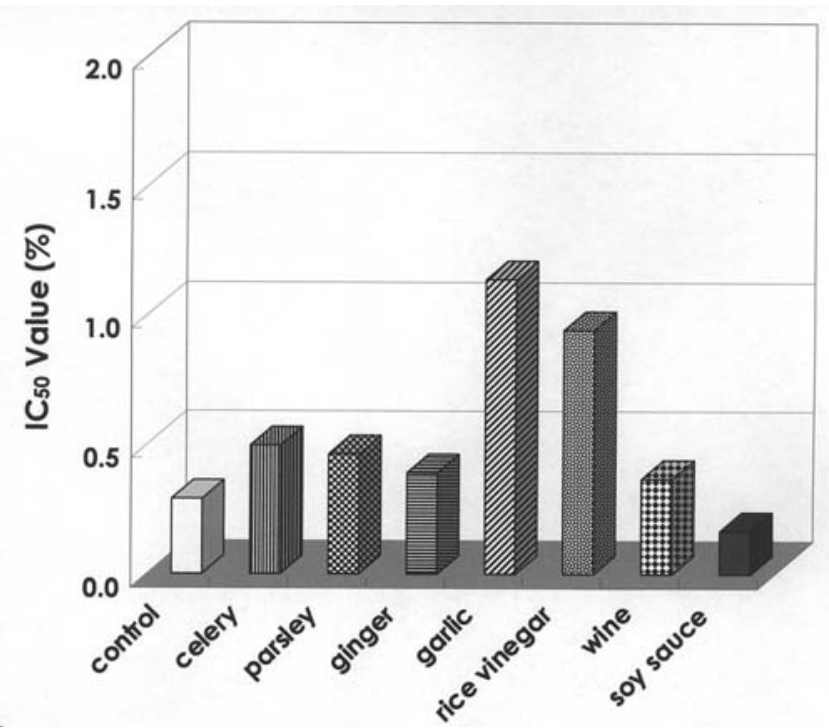

Figure 4. Effect of adding seasonings or spices on the $\mathrm{IC}_{50}$ value $(\%)$ of the peroxyl radical scavenging activity of chicken jelly 'Nikogori' soup heated at $100^{\circ} \mathrm{C}$ for $60 \mathrm{~min}$, measured by chemiluminescence. The white bar indicates only chicken wing meat (control); the other bars indicate the type of seasoning or spice added.

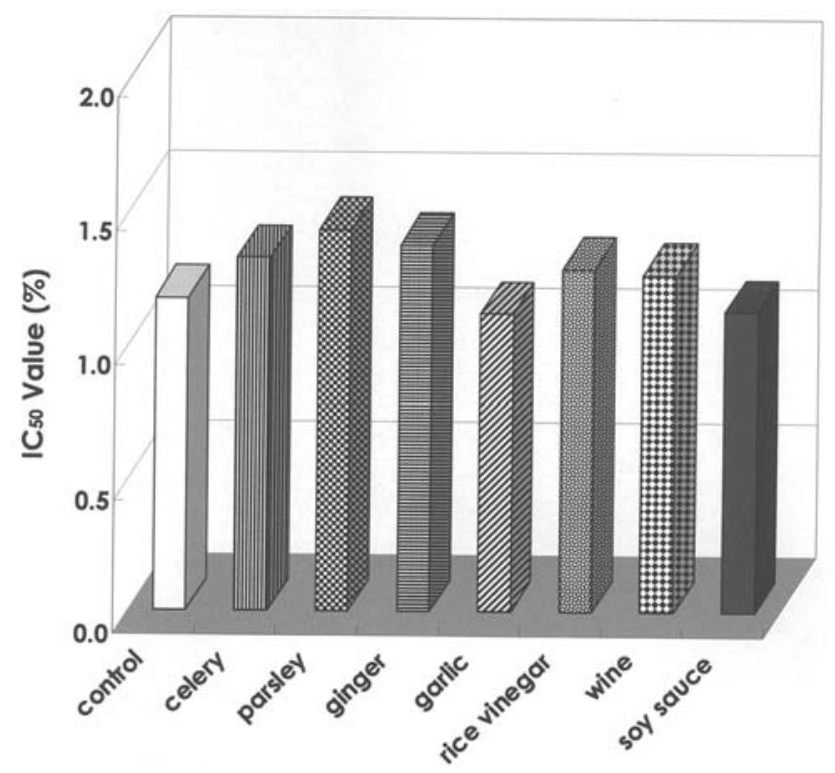

Figure 5. Effect of adding seasonings or spices on the $\mathrm{IC}_{50}$ value $(\%)$ of the hydroxyl radical scavenging activity of chicken jelly 'Nikogori' soup heated at $100^{\circ} \mathrm{C}$ for $60 \mathrm{~min}$, measured by ESR. Details of the symbols of the bars are described in the legend of Fig. 4.

was strongly indicated in only a few cases as compared with that of $90^{\circ} \mathrm{C}$. In contrast to the peroxyl radical scavenging activity, at $100^{\circ} \mathrm{C}$ for up to $60 \mathrm{~min}$, the scavenging activity of hydroxyl radical tended to be elevated. The $\mathrm{IC}_{50}$ values were $1.59,1.28,1.23$ and $1.16 \%$ for $10,20,30$ and $60 \mathrm{~min}$, respectively (Fig. 3). It has been reported that the hydroxyl radical can cause scissions of $\mathrm{N}$-glycosidic linkage between base and D-2-deoxyribose in DNA molecules, resulting in depurination (AP site) [15; Harada et al, Abstracts for Annual Meetings of the Japan Society for Cookery Science (in Japanese), p5, 2005]. It was assumed that the hydroxyl radical scavenging activity from chicken jelly 'Nikogori' soup could protect the break of DNA molecules from damage irrespective of the extracted heating time of the soup. Thus, the 'Nikogori' samples containing collagen degradation products extracted from chicken are assumed to contribute to peroxyl and hydroxyl radical scavenging activities, i.e. high antioxidative capacity.

Effect of adding seasonings or spices on the elevation of radical scavenging activity of chicken jelly 'Nikogori' soup. In the next experiment, due to the potential of unpalatable odors from 'Nikogori' dishes, the effects of adding various seasonings and spices were investigated. In fond de volaille, such as 'Nikogori,' and stews, various flavorings, spices or seasonings are generally added. The heating temperature and time were decided at $100^{\circ} \mathrm{C}$ for $60 \mathrm{~min}$ to be an appropriate cooking condition. The results are shown in Figs. 4 and 5. Although, the addition of garlic ( $\mathrm{IC}_{50}$ value, 1.14\%) largely inhibited the peroxyl radical scavenging activity compared to the control sample with no seasonings or spices $\left(\mathrm{IC}_{50}\right.$ value, $0.29 \%$ ) (Fig. 4), it slightly enhanced the hydroxyl radical scavenging activity $\left(\mathrm{IC}_{50}\right.$ value, $1.11 \%$ ) compared to the control ( $\mathrm{IC}_{50}$ value, $1.16 \%$ ) (Fig. 5). Rice vinegar also inhibited the peroxyl radical scavenging activity (Fig. 4). In our previous report, the addition of soy sauce to various 'Nikogori' gel samples prepared from fish and chicken wings was shown to enhance peroxyl radical scavenging activity (3). In the samples prepared from chicken in the present study, it was found that the addition of soy sauce not only enhanced the peroxyl radical scavenging activity, i.e. control sample $(0.29 \%)<$ soy sauce addition sample $(0.17 \%)$, but also slightly enhanced the hydroxyl radical scavenging activity, i.e. control $(1.16 \%)<$ soy sauce (1.12\%) (Figs. 4 and 5). However, the addition of other seasonings, such as wine, ginger, celery, and parsley, did not contribute to a change in $\mathrm{IC}_{50}$ values.

These results suggest that the addition of soy sauce seasoning in the boiled samples not only produces a better taste and fragrance but can also improve health by increasing the radical scavenging activity of the medicated diet, 'Yakuzen'. We conclude that the addition of some sauces is effective in enhancing the antioxidative capacity of chicken jelly 'Nikogori' soup. In the future, we aim to find suitable sauces for improving the taste and fragrance and increasing the antioxidative capacity of chicken jelly 'Nikogori' soup.

\section{Acknowledgments}

The authors are grateful to Ms. Nami Fukuda and Ms. Akiko Tsujimura (Laboratory of Marine Resource Processing, Department of Food Science and Technology, National Fisheries University) for their technical assistance with this research, and to Dr Fujiko Kawamura (Emeritus Professor, Faculty of Home Economics, Tokyo Kasei University) for her kind encouragement during this work.

\section{References}

1. Minari Y, Tokui N, Zhu GS and Guo X: Chinese medicine and Chinese medicated diet. J Integr Stud Diet Habits (in Japanese) 12: 109-114, 2001. 
2. Minari Y, Tokui N, Fukumoto A, Zhu GS, Guo X and Sugahara T: The classification of dietetic Chinese drugs for cooking Chinese medicated diet. J Integr Stud Diet Habits (in Japanese) 11: 277-287, 2000.

3. Nagatsuka N, Harada K, Ando M and Nagao K: Effect of soy sauce on the antioxidative capacity of the gelatin gel food 'Nikogori' measured using the chemiluminescence method. Int J Mol Med 16: 427-430, 2005.

4. Nagler-Anderson C, Bober LA, Robinson ME, Siskind GW and Thorbecke GJ: Suppression of type II collagen-induced arthritis by intragastric administration of soluble type II collagen. Proc Natl Acad Sci USA 83: 7443-7446, 1986.

5. Halliwell B and Gutteridge JMC: Role of free radicals and catalytic metal ions in human disease: an overview. In: Methods in Enzymology Volume 186, Oxygen Radicals in Biological Systems, Part B: Oxygen Radicals and Antioxidants. Packer L and Glazer AN (eds). Academic Press, London, pp1-85, 1990.

6. Harada K, Ando M, Kitao S, Sakamoto Y, Kobayashi M and Tamura Y: Measurement of antioxidative capacity of fish sauce using chemiluminescence method. Fish Sci 68 (suppl 2): 1437-1440, 2002.

7. Harada K, Okano C, Kadoguchi H, Okubo Y, Ando M, Kitao S and Tamura Y: Peroxyl radical scavenging capability of fish sauces measured by the chemiluminescence method. Int J Mol Med 12: 621-625, 2003.

8. Ando M, Harada K, Kitao S, Kobayashi M and Tamura Y: Relationship between peroxyl radical scavenging capability measured by the chemiluminescence method and an aminocarbonyl reaction product in soy sauce. Int J Mol Med 12: 923-928, 2003
9. Kitao S, Fujii K, Teramoto M, Harada K, Ando M and Tamura Y: Rapid and sensitive method for evaluation of radical-scavenging activity using peroxyl radicals derived 2,2'-azobis(2-amidinopropane) dihydrochloride and luminol chemiluminescence. Food Sci Technol Res 11: 318-323, 2005.

10. Isobe $\mathrm{Y}$, Kase $\mathrm{Y}$, Narita $\mathrm{M}$ and Komiya T: Antioxidative activity of the tropical fruit, Feijoa sellowiana Berg. J Home Econ Jpn (in Japanese) 54: 945-949, 2003.

11. Harada K: Radical scavenging capability of seafoods using the chemiluminescence and electron spin resonance methods. Int $\mathrm{J}$ Mol Med 14: S43, 2004.

12. Nagatsuka N, Harada K, Ando M and Nagao K: Antioxidative capacity of chicken jelly soup. Proceedings of the 13th Biennial International Congress of Asian Regional Association for Home Economics (ARAHE), p590, 2005

13. Kawamura $\mathrm{F}$ and Okada M: Antioxidative effect of ginger on the peroxidation of lard in boiled water (part 1); effect of the essential oils and sliced ginger. J Home Econ Jpn (in Japanese) 43: 31-35, 1992

14. Saiga A, Tanabe S and Nishimura T: Antioxidant activity of peptides obtained from porcine myofibrillar proteins by protease treatment. J Agric Food Chem 51: 3661-3667, 2003.

15. Lindahl T: Instability and decay of the primary structure of DNA. Nature 362: 709-715, 1993. 